\title{
A TEMÁTICA DA ALIMENTAÇÃO ESCOLAR NA FORMAÇÃO DO NUTRICIONISTA
}

Aline Guimarães de Almeida.

Orientador (a): Carolina Conceição Prado

\begin{abstract}
RESUMO
Introdução: O Programa Nacional de Alimentação Escolar (PNAE) brasileiro é o mais antigo Programa na área de Nutrição no país, e busca atender as necessidades nutricionais dos estudantes e formar hábitos alimentares saudáveis, durante sua permanência na escola. Para tanto, faz-se necessário a atuação de nutricionistas habilitados a assumirem responsabilidade técnica junto ao mesmo. Objetivo: Destacar a relevância do conteúdo relativo ao PNAE, na formação do nutricionista. Metodologia: Pesquisa documental, sendo o estudo desenvolvido em fases de identificar os documentos, destacar e analisar os dados. Pretendeu-se analisar a adequação do conteúdo programático abordado na disciplina de Alimentação Escolar do departamento de nutrição da Universidade de Brasília, com relação às atribuições do nutricionista no Programa Nacional de Alimentação Escolar. Resultados: O desenvolvimento da disciplina mostrou-se relevante para a formação dos graduandos, uma vez que o nutricionista atuante no PNAE possui diversas atribuições específicas, discutidas durante o curso. Esta disciplina na grade curricular do curso de nutrição é importante, pois esse profissional precisa estar preparado para atuar nesta área, sendo um agente fundamental para o alcance dos objetivos e desenvolvimento das atividades do Programa de Alimentação Escolar. Como este campo de atuação esta em crescimento, o nutricionista deve estar capacitado para uma efetiva atuação, com base no aprofundamento da discussão desta temática. Conclusão: O futuro nutricionista capacitado em alimentação escolar, é de vital importância para o desenvolvimento pleno do PNAE, cumprindo com qualidade as diversas atribuições específicas deste cargo. Para tanto, devem ser incentivadas ações como a apresentada neste trabalho, de criação e oferecimento de disciplina específica sobre a alimentação escolar, que dêem conta do vasto conteúdo relativo a este programa.
\end{abstract}

Palavras-chave: Programa Nacional de Alimentação Escolar, alimentação escolar, nutrição e Ensino Superior.

\section{INTRODUÇÃO}

O Programa Nacional de Alimentação Escolar (PNAE) é uma política governamental, de âmbito nacional, implantada oficialmente no ano de 1955, que garante, por meio da transferência de recursos financeiros, a alimentação a todos os alunos matriculados na educação básica de instituições de ensino públicas do Brasil (MUNIZ; CARVALHO, 2007; BRASIL, 2009a). Atualmente, o PNAE tem por 
objetivo contribuir para o crescimento e desenvolvimento biopsicossocial, a aprendizagem, o rendimento escolar e a formação de práticas alimentares saudáveis nos alunos, por meio de ações de educação alimentar e nutricional e da oferta de refeições que cubram as necessidades nutricionais dos indivíduos durante o período em que permanecem na escola (BRASIL, 2009b). Sendo assim, no intuito de alcançar plenamente estes objetivos, o Fundo Nacional de Desenvolvimento da Educação (FNDE) do Ministério da Educação do Brasil firmou parceria com instituições de ensino superior do país para a criação dos Centros Colaboradores de Alimentação e Nutrição do Escolar (CECANEs). Tais instituições surgiram com a finalidade de prestar assessoria e consultoria científica, técnica e operacional ao FNDE, estados e municípios para a adequada execução do PNAE, bem como para seu aprimoramento nas regiões de abrangência da instituição.

Além disso, por estar inserido dentro da universidade, o Centro Colaborador sediado no Departamento da Nutrição da Universidade de Brasília ficou responsável por ministrar a disciplina “Alimentação Escolar”, cujo objetivo é capacitar os estudantes de nutrição na temática relativa à segurança alimentar e nutricional e sua interação com o PNAE como uma política pública.

Sendo assim, verifica-se que a atuação do CECANE contribui de forma significativa para a maior efetividade, eficácia e eficiência do Programa.

Segundo o artigo 11 da Lei 11.947 de 2009 que dispõe sobre o atendimento da alimentação escolar e do Programa Dinheiro Direto na Escola aos alunos da educação básica, o nutricionista é responsável técnico da alimentação escolar nos Estados, no Distrito Federal, nos Municípios e nas escolas federais (BRASIL, 2009a).

Compete ao nutricionista que atua no Programa de Alimentação Escolar (PAE), programar, avaliar e executar os cardápios; planejar e coordenar a aplicação de testes de aceitabilidade; desenvolver programas de educação alimentar e nutricional para a comunidade escolar; identificar os alunos com as necessidades nutricionais; elaborar manual de Boas Práticas de Fabricação nas escolas; participar do processo de avaliação técnica de fornecedores de gêneros alimentícios segundo os padrões de identidade e qualidade, a fim de emitir parecer técnico; orientar e supervisionar as atividades de recebimento, higienização e armazenamento de alimentos; participar da seleção e capacitação do pessoal do PAE; colaborar na formação de profissionais na área de 
alimentação e nutrição dentre outras atribuições complementares (BRASIL, 2009b; CFN, 2005).

Para tanto, faz-se necessário a atuação de nutricionistas habilitados a assumirem responsabilidade técnica junto ao PAE.

Devido à importância da atuação do profissional nutricionista no PAE, como responsável técnico e como promotor da alimentação saudável dos alunos deste programa, este trabalho tem como objetivo destacar a relevância do conteúdo relativo ao PNAE, na formação do nutricionista. Para isto, pretende-se analisar a adequação do conteúdo programático abordado na disciplina de Alimentação Escolar do departamento de nutrição da Universidade de Brasília, com relação às atribuições do nutricionista no Programa Nacional de Alimentação Escolar descritas na Resolução nº 358, de 18 de maio de 2005, na Lei $n^{0}$ 11.947, de 16 de junho de 2009 e Resolução CD/ n ${ }^{0}$ 38, de 16 de julho de 2009.

\section{MATERIAL E MÉTODO}

\section{Tipo de pesquisa:}

Foi utilizada a pesquisa documental, sendo o estudo desenvolvido em fases de identificar os documentos, destacar e analisar os dados.

\section{Descrição geral da disciplina:}

Em 2008 e 2009 foi desenvolvida a Disciplina de Alimentação Escolar, iniciativa do Centro Colaborador em Alimentação e Nutrição do Escolar - CECANE da Universidade de Brasília - UnB, oferecida no Departamento de Nutrição com a denominação de Seminário Avançado: Nutrição Social. A disciplina foi optativa para os alunos de graduação de nutrição, com uma carga horária de 02 (duas) horas aulas / semanais, totalizando 02 (dois) créditos, carga horária total de 60 (sessenta) horas, contou no segundo semestre de 2008 com 10 alunos que estavam no $5^{\circ}$ semestre do curso de nutrição, no primeiro semestre de 2009 com 05 alunos que estavam no $6^{\circ}$ semestre e no segundo semestre com 10 alunos que estavam entre o $2^{\circ}$ e $8^{\circ}$ semestre do curso. Totalizando 25 alunos capacitados. 
O objetivo geral da disciplina foi capacitar os estudantes na temática relativa à segurança alimentar e nutricional e sua interação com o PNAE como uma política pública, abordando seus aspectos políticos, sociais, administrativos e nutricionais. Objetivou-se que o aluno ao final do curso: Reconheça a segurança alimentar e nutricional e o direito humano à alimentação adequada dentro do contexto da alimentação escolar; Identifique, dentro do contexto escolar, as políticas públicas e programas de alimentação e nutrição e as leis de regulamentação da alimentação; Identifique e analise os principais aspectos relacionados ao PNAE; Caracterize o controle social no PNAE, identificando a relevância do mesmo em relação a todos os atores envolvidos e Caracterize a relevância da educação nutricional no contexto do PNAE. Os principais temas trabalhados foram: Direito Humano à Alimentação Adequada e Segurança Alimentar e Nutricional; Alimentação, crescimento e desenvolvimento infantil; Cálculo de cardápio; teste de aceitabilidade; necessidades nutricionais dos escolares; Políticas Públicas e Programas, Legislações e Resoluções na área de Alimentação e Nutrição do escolar. Todos os conteúdos foram trabalhados com a interface na temática alimentação escolar.

A disciplina foi composta por aulas expositivas, debates, palestras, apresentação de artigos científicos e oficina culinária.

As formas de avaliação dos alunos na disciplina foram: apresentação de mural sobre alimentação e nutrição escolar, exercícios, avaliação escrita, seminário (apresentação de artigo), participação do aluno e interação com o grupo.

\section{Procedimento:}

Foram selecionados documentos recentes, como a Resolução $n^{\circ}$ 358, de 18 de maio de 2005, na Lei $n^{\circ}$ 11.947, de 16 de junho de 2009 e Resolução CD/ n 38, de 16 de julho de 2009 que tratam das atribuições do nutricionista no PNAE, que serviram de subsídios para a reflexão e análise do tema de pesquisa proposto. O conteúdo programático abordado na disciplina de alimentação escolar foi analisado de acordo com estes documentos e a literatura existente.

\section{Análise dos dados:}

As análises obtidas foram transcritas na forma de texto e tabelas. Tais resultados seguem no próximo tópico. 


\section{RESULTADOS E DISCUSSÃO}

Na tabela 1 demonstra os temas abordados na disciplina.

Tabela 1. Conteúdos abordados na disciplina.

\section{CONTEUDOS ABORDADOS NA DISCIPLINA}

A segurança alimentar e nutricional e o direito humano à alimentação adequada dentro do contexto da alimentação escolar.

As diretrizes da Política Nacional de Alimentação e Nutrição (PNAN) no contexto escolar.

Contribuições do Estatuto da Criança e do Adolescente com relação à alimentação.

A Lei Orgânica de Segurança Alimentar e Nutricional (LOSAN).

Leis de regulamentação da alimentação escolar nos estados.

Os aspectos legais da alimentação escolar.

O PNAE: histórico, conceito, abrangência e principais ações.

O controle social do PNAE: importância, papel dos Conselhos de Alimentação do Escolar e dos atores envolvidos.

Funções e ações do Fundo Nacional de Desenvolvimento da Educação frente ao PNAE.

Papel dos nutricionistas, gestores, conselheiros e das merendeiras para a eficácia da Alimentação Escolar.

A educação nutricional integrada ao Programa Nacional de Alimentação Escolar - PNAE: discussão de metodologias e apresentação de experiências bem sucedidas.

Teste de aceitabilidade e oficina culinária com preparações para escolares.

De acordo com Martins, 1993, p.100, diz que:

“A seleção dos conteúdos deve partir dos propósitos gerais para os objetivos e, a seguir, para o conteúdo da matéria, pois este consiste em um conjunto que envolve conhecimento, habilidades e atitudes e deve ser organizado a partir de fatos concretos, passando para os conceitos, daí para os princípios, e, finalmente, para níveis mais abstratos” (MARTINS, 1993, p. 100). 
Os conteúdos programáticos trabalhados na disciplina estão em consonância com os princípios e diretrizes do PNAE que estão relacionados com o Direito Humano à Alimentação Adequada, a Universalidade do atendimento da alimentação escolar; a garantia do alimento de maneira igualitária; emprego da alimentação saudável e adequada, contínua e sustentável; respeito aos hábitos alimentares; inclusão da educação alimentar e nutricional no processo ensino aprendizagem; descentralização das ações e comunicação com as outras políticas do governo e participação da comunidade no controle social (tabela 1).

A alimentação escolar é um direito do aluno matriculado na rede pública da atenção básica, e o Programa Nacional de Alimentação Escolar (PNAE), junto ao governo, é responsável por assegurar esse direito, contando com a participação de profissionais capacitados para oferecer e promover uma alimentação saudável, contribuindo com a Segurança Alimentar e Nutricional dos escolares. A Lei 11.947, de 16 de julho de 2009, propiciou importantes avanços no PNAE. Dentre eles, destacam-se a extensão do programa para toda a rede básica e pública, incluindo jovens e adultos (BRASIL, 2009a).

O grande desafio do CECANE é prestar apoio técnico e operacional na implementação da alimentação saudável nas escolas públicas das regiões Norte e Centro-Oeste, bem como desenvolver outras ações pertinentes à boa execução do Programa Nacional de Alimentação Escolar (PNAE), as quais são convergentes com os pilares das universidades que são: ensino, pesquisa e extensão. E a disciplina de alimentação escolar é uma estratégia para garantir futuramente esse desafio.

O desenvolvimento da disciplina mostrou-se relevante para a formação dos graduandos, uma vez que o nutricionista atuante no PNAE possui diversas atribuições específicas, discutidas durante o curso.

Esta disciplina na grade curricular do curso de nutrição é importante, pois esse profissional precisa estar preparado para atuar nesta área, sendo um agente fundamental para o alcance dos objetivos e desenvolvimento das atividades do Programa de Alimentação Escolar.

A presença do profissional nutricionista, como responsável técnico do PNAE, está respaldada pela Lei 11.947/2009 que rege esse programa (BRASIL, 2009a). Como 
este campo de atuação esta em crescimento, o nutricionista deve estar capacitado para uma efetiva atuação, com base no aprofundamento da discussão desta temática.

Destaca-se que a prática do nutricionista na alimentação escolar, não se limita só na elaboração de um cardápio, precisa está voltada para a promoção dos hábitos alimentares saudáveis dos alunos, com o desenvolvimento de ações de educação alimentar e nutricional. Por isso a importância da abordagem desse conteúdo na formação do nutricionista (BRASIL, 2009b).

A promoção de uma alimentação saudável consiste em importante instrumento de promoção da saúde. Segundo o art. 13 da resolução FNDE 38/ 2009, que dispõe sobre o atendimento da alimentação escolar aos alunos da educação básica do Programa Nacional de Alimentação Escolar, considera educação alimentar e nutricional “o conjunto de ações formativas que objetivam estimular a adoção voluntária de práticas e escolhas alimentares saudáveis, que colaborem para a aprendizagem, o estado de saúde do escolar e a qualidade de vida do indivíduo”. E considera dentre outras, a oficina culinária experimental com os alunos, uma estratégia de educação alimentar e nutricional (BRASIL, 2009b; PINHEIRO; et. al. 2006;' SANTOS, 2005). Foi realizada na disciplina uma aula prática com os alunos abordando esse tema.

Considerando a importância da escola como espaço propício à formação de hábitos alimentares saudáveis e à construção da cidadania, os Ministérios da Saúde e da Educação elaboraram conjuntamente no ano de 2006 a Portaria, n 1010/06, que "tem como finalidade o desenvolvimento de ações que garantam a adoção de práticas alimentares mais saudáveis no ambiente escolar e avaliação de seu impacto a partir da análise de seus efeitos em curto, médio e longo prazo” (BRASIL, 2006a). Para tanto, incentiva-se nesta portaria: ações de Educação Alimentar e Nutricional, observando sempre os hábitos alimentares regionais; o cultivo de hortas escolares como instrumento da Educação Alimentar e Nutricional e da interface com conteúdos de outras disciplinas curriculares, além do uso dos alimentos produzidos na alimentação escolar; a implantação das Boas Práticas de Fabricação nos serviços de alimentação escolar; a restrição ao comércio de alimentos e preparações com altos teores de gordura saturada, gorduras trans, açúcar livre e sal e incentivo ao consumo de frutas, verduras e legumes; e o monitoramento da situação nutricional dos escolares (PELICIONI; TORRES, 1999; BRASIL, 2006a). Essa portaria precisa ser apresentada e discutida com o futuro nutricionista que vai atuar no programa de alimentação escolar, pois ela trata da relação 
de diferentes setores do governo, fato esse muito importante para alcance dos objetivos dessa política pública da alimentação escolar.

Outro conteúdo importante que foi trabalhado na disciplina, foi a Política Nacional de Alimentação e Nutrição (PNAN) que foi publicada em 1999 e tem como propósitos a garantia da qualidade do alimento; promoção de práticas alimentares saudáveis; prevenção e controle de distúrbios nutricionais; e estímulos as ações intersetoriais que propiciem o acesso universal aos alimentos. Esses propósitos servem de base para as atribuições do nutricionista na alimentação escolar (BRASIL, 1999). Em 2006 foi aprovada a Política Nacional de Promoção da Saúde com o objetivo de promover a qualidade de vida e reduzir a vulnerabilidade e riscos à saúde relacionados aos seus determinantes e condicionantes tendo como uma de suas ações específicas a promoção da alimentação saudável com base nas diretrizes da PNAN e do Guia Alimentar da População Brasileira (BRASIL, 2006b).

O Conselho de Alimentação Escolar destaca-se como uma parte essencial no PNAE, pois ele é responsável pelo acompanhar e monitorar os produtos adquiridos, além de fazer parte do controle social do programa (BRASIL, 2006c). E o nutricionista deve contar com o apoio do conselheiro para alcançar os objetivos do PNAE.

\section{CONCLUSÃO}

O futuro nutricionista capacitado em alimentação escolar, é de vital importância para o desenvolvimento pleno do PNAE, cumprindo com qualidade as diversas atribuições específicas deste cargo. Os conteúdos abordados na disciplina de alimentação escolar são essenciais para que o esse profissional possa atuar de forma significativa na área.

Para tanto, devem ser incentivadas ações como a apresentada neste trabalho, de criação e oferecimento de disciplina específica sobre a alimentação escolar, que dêem conta do vasto conteúdo relativo a este programa.

\section{REFERÊNCIAS BIBLIOGRÁFICAS}

BRASIL. Fundo Nacional de Desenvolvimento da Educação. Lei 11.947, de 16 de junho de 2009. Dispõe sobre o atendimento da alimentação escolar e do Programa 
Dinheiro Direto na Escola aos alunos da educação básica; altera as Leis $n^{\circ}$ Leis nos 10.880, de 9 de junho de 2004, 11.273, de 6 de fevereiro de 2006, 11.507, de 20 de julho de 2007; revoga dispositivos da Medida Provisória no 2.178-36, de 24 de agosto de 2001, e a Lei no 8.913, de 12 de julho de 1994; e dá outras providências. Brasília, 2009a. Disponível em: http://www.fnde.gov.br/home/index.jsp?arquivo=/aliment acao_escolar/alimentacao_esc.html\#legislacao. [acesso em 10 de outubro de 2009].

BRASIL. Fundo Nacional de Desenvolvimento da Educação. Resolução CD/ $\mathbf{N}^{\mathbf{0}} \mathbf{3 8}$, de 16 de julho de 2009. Dispõe sobre o atendimento da alimentação escolar aos alunos da educação básica no Programa Nacional de Alimentação Escolar - PNAE. Brasília, 2009b. Disponível em: http://www.fnde.gov.br/home/index.jsp?arquivo=/alimentac ao_escolar/alimentacao_esc.html\#legislacao. [acesso em 10 de outubro de 2009].

BRASIL. Ministério da Saúde e Educação. Política Nacional de Alimentação e Nutrição, Brasília, 1999.

BRASIL. Ministério da Saúde e Educação. Portaria Interministerial 1.010, de 8 de maio de 2006. Institui as diretrizes para a Promoção da Alimentação Saudável nas Escolas de educação infantil, fundamental e nível médio das redes públicas e privadas, em âmbito nacional. Brasília, 2006a. Disponível em: http://dtr2001.saude.gov.br/sas/PORTARIAS/Port2006/GM/GM-1010.htm. [acesso em 3 de março de 2010].

BRASIL. Política Nacional de Promoção da Saúde. Ministério da Saúde. Brasília, 2006b.

BRASIL. Programa Nacional de Alimentação Escolar. Manual de orientação para os conselheiros e agentes envolvidos na execução do programa nacional de alimentação escolar. Ministério da Educação, Fundo Nacional de Desenvolvimento da Educação. Brasília, 2006c.

CONSELHO FEDERAL DE NUTRICIONISTAS (CFN). Resolução $\mathbf{n}^{\mathbf{0}}$ 358, de 18 de maio de 2005. Dispõe sobre as atribuições do Nutricionista no âmbito do Programa de Alimentação Escolar (PAE) e dá outras providências. Brasília, 2005. 
MARTINS, José do Prado. Didática geral: fundamentos, planejamento, metodologia,

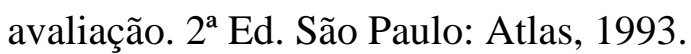

MUNIZ, Vanessa Messias; CARVALHO, Alice Teles de. O Programa Nacional de Alimentação Escolar no estado da Paraíba: um estudo sob o olhar dos beneficiários do Programa. Revista de nutrição, 20(3): 285-296, mai/jun, 2007.

PELICIONI, M. C. F.; TORRES, A. L. A Escola Promotora de Saúde [série monográfica $n^{\circ}$ 12]. São Paulo: Universidade de São Paulo, 1999.

PINHEIRO, A. R. O.; RECINE, E. G.; CARVALHO, M. F. C. C. As práticas alimentares saudáveis: a promoção da saúde no contexto da segurança alimentar e nutricional. In CASTRO A; MALO M. SUS: ressignificando a promoção da saúde. São Paulo: HUCITEC, 2006. p. 187-207.

SANTOS, Ligia Amparo da Silva. Educação alimentar e nutricional no contexto da promoção de práticas alimentares saudáveis. Rev. Nutr. 2005 Out; 18(5): 681-692. 